\title{
BNCC, Agenda Global E Formação Docente
}

\author{
National Learning Standards, Global Agenda, and Teacher Education
}

BNCC, Agenda Mundial y Formación Docente

\author{
ÁLVARO MOREIRA HYPOLITO* \\ Universidade Federal de Pelotas, Pelotas- RS. Brasil.
}

\begin{abstract}
RESUMO:O texto discute a BNCC como parte de uma agenda global e sua influência nas políticas de formação docente. A fim de contribuir com a discussão, o texto está organizado com o objetivo de mostrar relações entre políticas globais e políticas curriculares nacionais, para discutir essas políticas e formação docente. Demonstra que há uma agenda global estruturada localmente, a partir de grupos hegemônicos, nem sempre coesos, mas que têm obtido sucesso em impor suas propostas, mudando profundamente a formação docente.

Palavras-chave: Currículo Nacional. Reforma Educacional. Formação Docente.
\end{abstract}

\begin{abstract}
The paper discusses the Brazilian National Learnings Standards (BNCC) as part of a global agenda and its influence on teacher education policies. In order to contribute to the discussion, the text aims at showing relationships between global policies and national curriculum policies, to discuss these policies and teacher education. It demonstrates that there is a locally structured global agenda, based on hegemonic groups, not always cohesive, but that have been successful in imposing their proposals and changing teacher education.

Key-words: National Learning Standards, Educational Reform, Teacher Education.
\end{abstract}

* É doutor em Curriculum and Instruction na Universidade de Wisconsin, Madison. É Professor Titular da Universidade Federal de Pelotas, onde exerceu a função de Pró-Reitor de Graduação. Atualmente é o Coordenador do Programa de Pós-Graduação em Educação e coordena o CEPE da UFPel. E-mail: $<$ alvaro.hypolito@gmail.com>. 
RESUMEN: El texto discute el BNCC como parte de una agenda global y su influencia en las políticas de formación docente. Con el fin de contribuir a la discusión, el texto está organizado con el objetivo de mostrar las relaciones entre las políticas globales y las políticas curriculares nacionales, para discutir estas políticas y la formación docente. Demuestra que existe una agenda global estructurada localmente, basada en grupos hegemónicos, no siempre armoniosos, pero que han tenido éxito en imponer sus propuestas, cambiando profundamente la formación docente.

Palabras clave: Curriculum Nacional. Reforma Educativa. Formación Docente.

A Base Nacional Comum Curricular é o resultado de longos embates em torno da definição de um Currículo Nacional para a educação brasileira. Desde os anos de 1990, após a aprovação da Constituição de 1988 e o início da discussão de uma nova LDB, começam a existir, de forma mais intensa, debates em torno do que deveria ser um currículo para a Educação Básica, por vezes, um debate menos direto, por vezes, mais direto. Logo após a aprovação da nova LDB, em 1996, este debate aparece com mais força com a discussão dos Parâmetros Curriculares Nacionais (SILVA; GENTILI, 1996; BRASIL, 1997). De lá para cá, houve uma série de debates, ações, movimentos, críticas, defesas (nem sempre muito explícitas) em torno da necessidade ou não de um currículo nacional.

Nesse sentido, tivemos primeiro a definição dos Parâmetros Curriculares Nacionais, Parâmetros em Ação, Diretrizes Curriculares Nacionais e, no debate do último PNE, outros conceitos foram sendo introduzidos, tais como "expectativas de aprendizagem", "direitos de aprendizagem", ora para confundir, ora para reintroduzir o tema do currículo nacional, dada a baixa recepção nas escolas e entre pesquisadores da área. De todo modo, sempre houve, mesmo que de modo sub-reptício, uma mobilidade pela definição de uma base nacional até que se chegou a uma proposta de Base Nacional Comum Curricular, que passou a ser defendida seja pelo MEC, por muitos think tanks cada vez mais influentes, seja via entidades não-governamentais, fundações ou consultorias privadas, e por muitos acadêmicos, em geral de fora do campo do currículo, pois a ANPEd e o GT-Currículo sempre se posicionaram contrários a uma definição de currículo nacional.

O movimento Todos pela Educação desempenhou, nos últimos anos, um papel decisivo para a agenda educacional, em especial para que a educação brasileira se torne compatível com a agenda global (MARTINS, 2016). O Todos pela Educação e as entidades que gravitam sob sua influência, bem como vários órgãos governamentais e associações 
de dirigentes educacionais, passaram a desempenhar um papel determinante para a aprovação da BNCC (AVELAR; BALL, 2019). O Movimento pela Base é um exemplo desse tipo de articulação.

Para contribuir com a discussão sobre a BNCC relacionada com uma agenda global e com a formação docente, este texto está organizado em três seções: i) uma primeira, que tem por objetivo mostrar algumas relações entre políticas globais e políticas curriculares nacionais; ii) uma segunda, que visa relacionar a BNCC com políticas nacionais mais amplas; iii) e, por fim, uma discussão sobre essas políticas e a formação docente.

\section{Uma agenda global a ser cumprida localmente}

Por intermédio de alguns documentos e de análises realizadas por pesquisadores, pretende-se apresentar aportes bem definidos, articulados por agências multilaterais, para definir um projeto de educação que esteja articulado com um projeto global de educação.

Pelo menos desde 2001, vem sendo articulado um movimento global denominado GERM - Global Education Reform Moviment (Movimento Global de Reforma da Educação), que visa fortalecer as reformas educacionais por meio do que chama de eficácia dos sistemas educacionais. Está articulado em torno de três princípios da política educacional: padrões, prestação de contas e descentralização. De forma sintética, esses princípios do GERM, são apresentados na Tabela 1, conforme Verger e colaboradores (2018).

Nos três eixos destacados, estão definidas as orientações para as políticas que devem ser perseguidas. Em termos de padronização, basicamente está prescrito um currículo nacional que estabeleça padrões de qualidade, a partir de avaliações nacionais com metas e padrões de aprendizagem alcançáveis. Em termos de descentralização, advoga-se a transferência de competências e de responsabilidades para os níveis locais de administração do sistema escolar, de modo que as avaliações nacionais sirvam para responsabilizar e controlar as autoridades em seus diferentes níveis de competência. Esta descentralização tem por meta responsabilizar as equipes diretivas e as escolas pelo desempenho nas avaliações e, assim, os sistemas de avaliação são utilizados como um governo a distância, por meio de uma gestão de resultados. Em termos de accountability, tanto no sentido de responsabilização como de prestação de contas, os atores educacionais são responsabilizados pelo desempenho/performance por intermédio de avaliações com consequências, o que pretende ser alcançado tanto por uma accountability administrativa, em que os resultados dos exames são vinculados a prêmios ou sanções, na forma de incentivos salariais ou de recursos financeiros ou materiais para as escolas, e/ou por uma accountability de mercado, em que os resultados são utilizados tanto para políticas de escolha escolar como para incentivar a competição entre escolas. 


\section{Tabela 1 - O papel das avaliações nacionais para o GERM ${ }^{1}$}

\begin{tabular}{|l|l|l}
\hline $\begin{array}{l}\text { Princípios } \\
\text { GERM }\end{array}$ & Definições e principais políticas & Função das avaliações nacionais \\
\hline Padronização & $\begin{array}{l}\text { Prescrição de um Currículo Nacional } \\
\text { e estabelecimento de padrões de } \\
\text { qualidade }\end{array}$ & $\begin{array}{l}\text { Avaliações nacionais para garantir } \\
\text { que alcancem as metas e adiram a } \\
\text { padrões de aprendizagem avaliáveis }\end{array}$ \\
\hline & $\begin{array}{l}\text { Transferência de competências e } \\
\text { autoridade de um governo central } \\
\text { para níveis mais locais de gestão }\end{array}$ & $\begin{array}{l}\text { Avaliações nacionais utilizadas para } \\
\text { controlar as autoridades estatais, } \\
\text { regionais e locais }\end{array}$ \\
\hline Descentralização & $\begin{array}{l}\text { Devolução das responsabilidades } \\
\text { gerenciais e/ou pedagógicas para } \\
\text { diretores e escolas }\end{array}$ & $\begin{array}{l}\text { Avaliações nacionais utilizadas } \\
\text { para governar a distância inúmeros } \\
\text { prestadores autônomos por meio dos } \\
\text { princípios da gestão de resultados }\end{array}$ \\
\hline Accountability & $\begin{array}{l}\text { Atores educacionais } \\
\text { responsabilizados por suas ações e } \\
\text { resultados por meio de algum tipo } \\
\text { de avaliação com consequências }\end{array}$ & $\begin{array}{l}\text { Accountability Administrativa - } \\
\text { resultados dos exames vinculados } \\
\text { a incentivos ou sanções a escolas, } \\
\text { diretores e docentes; }\end{array}$ \\
\hline $\begin{array}{l}\text { Accountability de mercado - } \\
\text { resultados para auxiliar nas políticas } \\
\text { de escolha escolar e promover a } \\
\text { competição entre escolas; }\end{array}$ \\
\hline
\end{tabular}

Fonte: VERGER; PARCERISA; FONTDEVILA, 2018, [Tradução livre].

Como se pode observar, o tema do currículo nacional está associado com processos de avaliação e testes padronizados e diretamente vinculado a essas políticas sedimentadas como programa de uma reforma global.

Dois documentos do Banco Mundial são importantes para evidenciar outros aspectos deste projeto e para relacioná-lo com uma agenda mais ampla. Lois Weiner e Mary Compton (2016) analisam o documento do Banco Mundial "Professores excelentes - como melhorar a aprendizagem dos estudantes na América Latina e no Caribe", assinado por Burnes e Luque (2015), e destacam algumas cinco premissas que consideram a base do entendimento deste documento. Segundo as autoras, as premissas são:

- Premissa 1: a pobreza na América Latina e Caribe pode ser mais efetivamente reduzida por intermédio da reforma educacional.

Isso quer dizer que o mito de que a educação é a redenção de todos os males ainda persiste, embora os investimentos em educação sejam precários e insuficientes na região. A solução da desigualdade social é deslocada da economia e da política para a reforma educacional. O problema da pobreza passa a ser resolvido por uma solução da reforma 
educacional: melhorar a qualidade da escola. A qualidade da escola obviamente concebida como a qualidade dependente dos testes, das avaliações e do mercado.

- Premissa 2: a América Latina e o Caribe constituem um contexto político, econômico, social e educacional único em que a mesma política educacional pode ser aplicada com efeito igual e positivo.

Esta segunda premissa reafirma a reforma global, haja vista que, se com pequenos ajustes, dado que uma ampla região como a América Latina e o Caribe constituem um contexto único, uma mesma política educacional pode ser aplicada sem prejuízo. Portanto, basta transferir para contextos locais, políticas pensadas globalmente. Stephen Ball (2014), considerando os diferentes atores e contextos, bem como as dinâmicas próprias de cada contexto, prefere denominar tais processos como mobilidade de políticas e não transferência, no sentido de que tais políticas são deslocadas e adaptadas de acordo com interesses globais e locais. Ademais, as políticas globais somente se deslocam, se movem e são aceitas, porque coincidem com os interesses das elites locais e porque, nas relações globais, uns têm mais poder que outros, por isso importa saber quem globaliza quem (SANTOS, 2002). É evidente que este é sempre um processo impositivo, estruturalmente agendado com base em interesses socioeconômicos do desenvolvimento do capitalismo global, e que a premissa colocada como uma possibilidade líquida e certa é um engodo para justificar a própria reforma, como se diferentes contextos não exigissem diferentes alternativas educativas.

- Premissa 3: melhorar a qualidade docente, conforme capturada pelo desempenho dos estudantes em testes padronizados e medidas de valor agregado (vam), é a forma mais eficaz de melhorar os resultados educacionais na América Latina e Caribe.

Reduzir a aferição da qualidade do trabalho docente a resultados de testes padronizados e mesmo a medidas de valor agregado é reduzir a qualidade do trabalho docente a testes de múltipla escolha. Em estudo anterior, Ivo e Hypolito (2017) demonstram que uma mesma docente de Séries Iniciais trabalhava em duas escolas públicas, uma com o melhor IDEB e outra com o pior IDEB do município, o que impõe o incontornável fato de que o desempenho nos exames é relativo a muitos fatores e que a qualidade do trabalho docente não pode ser aferida por métricas simplistas. As condições de trabalho e de salário a que o magistério está submetido são muito precárias, estando as escolas públicas, elas próprias, em condições também muito precárias. Além disso, o financiamento da educação pública é bastante insuficiente, assim como a formação docente, que está submetida a regras e condições muito distantes daquelas consideradas adequadas. Com efeito, esta premissa é absolutamente inadequada para aferir qualidade docente. 
- Premissa 4: a baixa qualidade docente, medida pelo uso do tempo de ensino, demonstra que a composição do magistério deve ser mudada.

A medida utilizada para indicar a baixa qualidade docente de acordo com o tempo de ensino é muito criticada pelas autoras Weiner e Compton (2016). Além de indicar a imprecisão dos instrumentos utilizados e sua inadequação por serem aplicados fora de contexto (instrumento criado e testado nos EUA, aplicado com classes de crianças de países em desenvolvimento). Nas páginas 8 e 9 do referido artigo, as autoras mostram que tanto o instrumento quanto a pesquisa que origina o relatório do Banco Mundial, neste particular, são criticados por outro documento do próprio Banco, e não está citado no relatório que expressa a premissa 4 . Além disso, o estudo não leva em conta outros trabalhos, os quais demonstram que crianças e docentes em um mesmo contexto cultural podem elevar a proficiência, em razão do desenvolvimento de uma pedagogia culturalmente relevante, em que os tempos de ensino não coincidem com as métricas de estudos com vieses quantitativos fora de contexto.

- Premissa 5: o obstáculo primário para melhorar a educação pela elevação da qualidade docente é o poder político dos sindicatos de professores, os quais, por esse motivo, devem ser profundamente enfraquecidos.

Esta última premissa expressa a visão política há muito enfatizada pelo neoliberalismo: os sindicatos docentes são corporativos; não compreendem a necessidade da reforma; emperram e boicotam qualquer iniciativa de melhorar a qualidade do ensino; etc. etc. etc. Tais argumentos são bem conhecidos.

De fato, os sindicatos docentes têm sido uma base importante de resistência às reformas e o único caminho para melhorar as condições de trabalho do professorado. Os sindicatos têm sido cruciais para reivindicar mais financiamento para a educação pública, melhoria das condições de trabalho e da oferta educacional, em termos de condições físico-materiais das escolas, bem como para garantir uma autonomia do trabalho e da liberdade de expressão no ensino. Em períodos como o que estamos vivendo, grande parte das críticas aos docentes foi redirecionada para um conteúdo neoconservador, e grupos como o MBL e Escola sem Partido vêm assumindo a liderança dos ataques ao magistério. $^{2}$

Essa pode ser mais uma demonstração da aliança neoliberal, neoconservadora, com grupos populistas-autoritários e setores da classe média, aliança sobre a qual Apple (1999; 2000; 2003), desde a última década do século passado, vem nos alertando, em função do crescimento do que ele chama Modernização Conservadora, e muitos de nós ficamos surpresos que ela esteja hegemônica entre nós. Para esta aliança, os sindicatos docentes são uma ameaça à sociedade tradicional, conservadora e religiosa. 
Está nesta mesma linha, ou pelo menos conectado a ela, o relatório publicado pelo Banco Mundial: “Um ajuste justo - análise da eficiência e equidade do gasto público no Brasil" (2017). Após uma década de crescimento econômico, o Brasil, com uma economia dirigida por economistas de grupos financeiros, começa a entrar em crise, que perdura até hoje, e, com este relatório, o Banco Mundial indica uma série de medidas para um ajuste "justo". Dentre elas, há algumas para o campo educacional, que vale muito a pena transcrever para ilustrar a abrangência dessas políticas.

As sugestões para o campo educacional incluem reformas para aumentar, segundo a visão já conhecida do Banco, a eficiência e a equidade, com o objetivo de reduzir o custo fiscal. Segundo o relatório, quanto ao Ensino Fundamental e Médio, é possível economizar algo em torno de $1 \%$ do PIB com a melhoria da eficiência nesses níveis de ensino, sem comprometer os serviços prestados.

Algumas opções de reforma para aumentar a eficiência nesses níveis de ensino encontram-se resumidas abaixo:

i. Permitir o aumento da razão aluno-professor nas escolas mais ineficientes para, gradualmente, chegar a níveis de eficiência por meio da não reposição dos professores que se aposentarem. Em média, a fronteira de eficiência seria atingida no ensino fundamental até 2027, se os professores aposentados não forem repostos; no ensino médio, a fronteira seria atingida até 2026. Somente esta medida economizaria até $0,33 \%$ do PIB. Outra recomendação para os municípios que precisarem repor os professores que se aposentarem seria limitar a contratação de novos professores concursados, cuja demissão é extremamente difícil e cujos custos são significativos, uma vez que eles se aposentam cedo com vencimentos integrais.

ii. Expandir e compartilhar experiências positivas de gestão escolar que demonstraram bons resultados em vários estados e municípios do país. Alguns bons exemplos (...) são: a nomeação dos diretores escolares com base em seu desempenho e experiência (e não por indicações políticas); o pagamento de bônus aos professores e funcionários com base no desempenho das escolas; a adaptação das políticas estaduais a necessidades locais específicas; o compartilhamento de experiências e melhores práticas; e o destaque às escolas com desempenho melhor. A contratação de empresas privadas para o fornecimento de serviços de educação também poderia melhorar o desempenho e a eficiência dos gastos públicos com educação. As escolas charter provavelmente teriam mais flexibilidade para gerir seus recursos humanos. Por poderem ser penalizadas por mau desempenho, elas baseariam as decisões sobre contratação, demissão, promoções e salários no desempenho individual dos professores, e não em sua estabilidade ou antiguidade. No entanto, talvez sejam necessárias novas leis federais, estaduais e municipais para permitir PPPs no Ensino Básico. (2017, p. 136-7)

As recomendações contidas neste relatório já são conhecidas de muitos gestores e algumas delas são aplicadas ou já foram experimentadas em alguns dos sistemas municipais ou estaduais de educação. Custa a crer que tais recomendações tenham sido feitas por especialistas da educação, certamente, não por muitos, mas, com certeza, com o aval de alguns. Propor o aumento de estudantes por turma para "equilibrar" o número de docentes é algo completamente fora da realidade da educação no país, onde já há turmas 
enormes e, mesmo que fossem pequenas, são classes de difícil manejo pedagógico, dadas as desfavoráveis condições sociais, econômicas e culturais em muitas comunidades. A não reposição de docentes aposentados vai provocar o caos em muitos sistemas.

A gestão democrática, além de ser uma garantia legal, foi uma conquista de muitos movimentos sociais e docentes, assim a eleição de diretores e de conselhos escolares é uma experiência bem exitosa em muitas escolas públicas e frequentemente está associada à melhoria de desempenho da escola e dos estudantes (LEITE et al, 2012), de modo mais positivo para as comunidades do que modelos político-administrativos behavioristas de compensação, prêmios e punições, como o que está sugerido no documento do Banco, tipo pagamento de bônus por desempenho escolar. Experiências de gestão democrática e de projetos pedagógicos coletivos exitosos não são divulgados. Práticas gerenciais de cunho pragmático, no entanto, são amplamente recomendadas.

A privatização de serviços e de escolas, seja pelo incremento das parcerias público-privadas, seja pelo estímulo às escolas charter, são experiências já muito bem analisadas e com resultados pífios, como demonstra Diane Ravitch (2010), ao analisar a educação nos EUA, e Freitas (2018), ao discutir as políticas nacionais como a Reforma Empresarial da Educação. Tanto nos EUA como no Brasil, o posicionamento na classificação de desempenho no exame PISA (sistema de avaliação internacional da OCDE) mantém-se com pouca alteração há vários anos. No caso brasileiro, há décadas. Os avanços na melhoria da qualidade da educação no Brasil, após algumas décadas de gerencialismo na Educação, são pífios, para não dizer vergonhosos frente ao investimento de milhões de reais nos sistemas de avaliação federal, estaduais e municipais.

\section{BNCC como política global/local}

É nesse contexto local e global que a reforma curricular BNCC foi constituída, com o apoio de grupos e instituições ligadas ao Todos pela Educação e por lobbies de fundações, institutos e entidades, com ou sem fins lucrativos, com interesses muito definidos em torno de um mercado educacional bilionário que envolve venda de materiais pedagógicos, consultorias privadas e prestação de serviços, a fim de substituir o que hoje é realizado pelas escolas e pelo sistema público de educação. ${ }^{3}$

O modelo é o gerencialismo pretendido pelo GERM e pelas políticas neoliberais. Este modelo, que implica em parcerias público-privadas, com a terceirização da produção de materiais didáticos e venda de sistemas apostilados, com a inclusão de sistemas de gestão educacional, na forma de aplicativos ou plataformas digitais, que monitoram todo o sistema administrativo e pedagógico, retira das escolas e do professorado o controle sobre o que deve ser ensinado e como deve ser ensinado. 
A promessa é que, com essa linha de trabalho, a qualidade do ensino vai atingir os melhores índices do IDEB. Para melhor averiguar o andamento dessa melhoria é preciso que se desencadeiem ações de accountability e de responsabilização, a fim de que a "sociedade" possa verificar o mais próximo possível do tempo real qual é o desempenho da educação de seus filhos. Para que essa dinâmica seja verdadeira, é necessário e imprescindível, que coexista com tais ações um sistema amplo de avaliação, o que pode ser denominado sistema de avaliação em larga escala. Atualmente, modelos de provas e avaliações desse tipo tornaram-se quase uma regra para estados e municípios, embora haja um sistema bastante complexo já organizado em nível federal.

Nesse ambiente, é que políticas de controle sobre os livros didáticos e uso de variados tipos de materiais de ensino passam a ser exigidos em escala, a fim de tornar objeto de mercado todos os materiais, inclusive aqueles que são distribuídos pelas redes públicas. Como mencionado anteriormente, tais políticas incluem sistemas de gestão que estão muito em uso e são significativamente rentáveis, pois muitos cobram pelo número de senhas utilizadas no sistema (SILVA, 2018) ${ }^{4}$.

Essas dinâmicas propostas para a educação pública obtêm êxito somente se forem acompanhadas de testes e exames padronizados, preconizados pelos sistemas de avaliação em voga. É com esta lógica que uma base nacional curricular passa a ser imprescindível.

Muitos dos argumentos em defesa de uma base curricular são sedutores, pois apresentam um discurso que aparenta ser verdadeiro: como as crianças de classes trabalhadoras, pobres, com pouco capital cultural, poderão ficar sem direitos de aprendizagem? como poderão obter um conhecimento valioso se não estiver garantido um currículo que seja comum para todos? Muitos acadêmicos respeitáveis, a meu ver, embarcaram nessa canoa furada e trabalharam muito para obter o melhor produto possível, em termos de qualidade curricular. Muitos contribuíram na elaboração tanto da primeira como da segunda versão da BNCC. A terceira versão já foi bastante conservadora e não absorveu muitos dos preceitos liberais para uma educação pública.

Apple (1999) alertava que a definição de um conhecimento oficial significa a exclusão de vozes e de culturas subalternas. A confluência de interesses em torno da definição de um currículo nacional ou de um conhecimento oficial, portanto, pode ser contraditória. Muitos aspectos são negociáveis. Outros não são negociáveis. Enquanto grupos neoliberais podem não ter preconceitos a minorias LGBT, grupos neoconservadores e religiosos podem ser muito homofóbicos e racistas. É por essas contradições que o controle sobre os conteúdos dos livros didáticos não é pouca coisa, pois se trata de publicar visões sobre gênero, família, evolucionismo, criacionismo, dentre muitos temas polêmicos em torno do currículo (Apple, 2003).

Regra geral, a definição de um currículo nacional pressupõe uma homogeneização cultural, pois algumas vozes calarão e outras poderão ser ensurdecedoras. Pode-se caminhar para um empobrecimento curricular. A justiça curricular que seria possível 
com uma melhor distribuição de conhecimento, muitas vezes, precisa ser desigual. Não se pode aceitar uma escola pobre para as populações pobres.

A terceira versão da BNCC passa a ter mais influência e controle de grupos neoconservadores e populistas-autoritários. Praticamente todo o grupo vinculado à academia retirara-se ou fora excluído. A versão resultante, além dos problemas advindos de qualquer ideia de base nacional, apresenta ainda conteúdos muito retrógrados e conservadores, pois, mesmo que grupos alinhados com a política neoliberal ocupassem cargos no Ministério da Educação, não conseguiram barrar a influência de grupos mais conservadores, como o movimento Escola sem Partido. $\mathrm{O}$ tema em torno de gênero, por exemplo, foi retirado completamente.

Todavia, grupos neoliberais apoiaram a eleição do atual presidente com a ilusão de que manteriam o controle sobre as políticas mais neoliberais, incluindo a BNCC, sistemas de avaliação, provas nacionais, formação docente e negociando, inclusive, a indicação do futuro ministro. Grupos religiosos e conservadores, entretanto, atuaram decisivamente para bloquear indicações mais liberais e impuseram uma indicação mais conservadora ideologicamente, logo, mais alinhada com os princípios da Escola sem Partido, do criacionismo e de uma visão conservadora de gênero, atacando o que chamam de ideologia de gênero.

Atualmente, o MEC ainda convive com problemas internos oriundos dessas disputas, mas já expressa políticas ultraliberais e neoconservadoras sobre a Educação Básica e a Educação Superior, retirando recursos de ambas e prometendo políticas privatistas para as universidades.

Nesse ambiente ainda incerto em muitos aspectos, a própria política de implantação da BNCC está confusa por parte do MEC, sendo que muitos estados e municípios aguardam iniciativas, uma vez que no presente momento não se sabe qual vai ser a estratégia para as ações referentes à BNCC. Nem mesmo as parcerias com fundações e entidades, que teriam um papel nesse processo de implantação como assessoria aos estados, estão definidas.

\section{BNCC e Formação Docente}

Hoje a escola está crivada por políticas que pretendem submetê-la cada vez mais ao mercado e ao neoconservadorismo. Não obstante, o controle sobre o cotidiano escolar em muito passa pelo controle da formação docente. Assim, os efeitos do gerencialismo e do conservadorismo sobre o currículo, sobre a gestão e sobre o trabalho docente são profundos e atingem o cotidiano escolar. As políticas de avaliação reforçam todo este apelo conservador em relação à escola, contudo as ações docentes de resistência estão presentes na reinterpretação e na tradução das políticas, conforme analisa Ball e colaboradores (2012). Uma dessas ações passa pela formação docente. 
As novas diretrizes para os cursos de Licenciaturas, aprovadas pelo CNE e que deveriam estar implantadas em todas as universidades, têm sido adiadas e ficado em suspenso, o que leva a crer que novas diretrizes estão sendo pensadas, mas não discutidas. As diretrizes aprovadas pelo CNE passaram por um processo bastante abrangente de discussão. É uma proposta que tenta solucionar um impasse antigo nos cursos de formação: compatibilizar o aumento de carga horária geral com o aumento de horas teóricas de fundamentação e o também aumento de horas de prática, sem dicotomia na formação.

O que se tem observado, no entanto, como tendência no contexto das reformas é o aligeiramento dos cursos de formação, seja em cursos rápidos ou condensados e simplificados ministrados por faculdades de qualidade duvidosa, seja em cursos a distância ou em cursos baratos voltados para uma formação focada no mercado.

A política nacional de formação docente vinha convergindo para uma lógica, do ponto de vista do método, muito próxima da BNCC. A dinâmica seria algo como descrito na Figura 1:

Figura 1. Encadeamento legal para a BNCC e a Política Nacional de Formação

\begin{tabular}{|c|c|c|c|}
\hline $\begin{array}{l}\text { Constituição } \\
\text { Federal }\end{array}$ & $L D B$ & $\begin{array}{l}\text { Política Nacional } \\
\text { Curricular }\end{array}$ & $\begin{array}{l}\text { Diretrizes } \\
\text { Nacionais }\end{array}$ \\
\hline & & & \\
\hline \multicolumn{2}{|c|}{$\begin{array}{l}\text { Base Nacional } \\
\text { Comum Curricular }\end{array}$} & \multicolumn{2}{|c|}{$\begin{array}{l}\text { Política Nacional de } \\
\text { Formação de Professores }\end{array}$} \\
\hline
\end{tabular}

Um dos argumentos que busca sustentar a imposição legal da BNCC é a determinação em lei da necessidade de uma Política Nacional Curricular. Ora, uma Política Nacional Curricular já tivemos com os Parâmetros e com as Diretrizes Nacionais e isso bastava para as escolas desenvolverem seu trabalho, o que para muitos já era criticado como um tipo de currículo nacional. A literatura sobre tal questão é vasta. Mas isso sempre foi insuficiente para quem advoga que para melhorar a qualidade da escola pública é necessária uma educação gerencialistas, voltada aos interesses bilionários do mercado.

Ainda não temos uma BNCC para a formação docente, mas este poderá ser o próximo passo, para alguns, pois para outros grupos, que advogam a necessidade de desregulamentar a formação docente no sentido de que qualquer pessoa graduada em qualquer área com uma rápida formação possa ser professor, nem tal iniciativa será necessária. Isso não está distante, como se pode ver pela semelhança dos programas Teach for All, Teach for America, Teach First e Ensina Brasil. 
Os modelos de formação docente adotados pelo Teach For All são esquemas fortemente patrocinados e apoiados por corporações e pelas novas filantropias privadas. Teach for All é um esquema global, uma versão mais articulada do Teach For America (EUA) e do Teach First (Inglaterra e países sob sua influência). A versão brasileira é o Ensina! Brasil. Teach for All descreve-se como "[...] uma rede global de empreendedores sociais trabalhando para expandir as oportunidades educacionais em seus países [...] sua missão é expandir internacionalmente as oportunidades educacionais aumentando e acelerando o impacto desses empreendimentos sociais." (BALL et al, 2013, p.17, nota 1).

O programa Ensina Brasil faz parte da rede Teach for All. O programa apresenta a seguinte proposta: recrutar graduados de boas universidades, fazer uma formação básica de 250 horas e uma parte de formação continuada de 1830 horas, para dar aulas em escolas vulneráveis, com remuneração, como mostrado na página do programa e na figura 2.

Figura 2 - Síntese da proposta de formação docente do ENSINA BRASIL

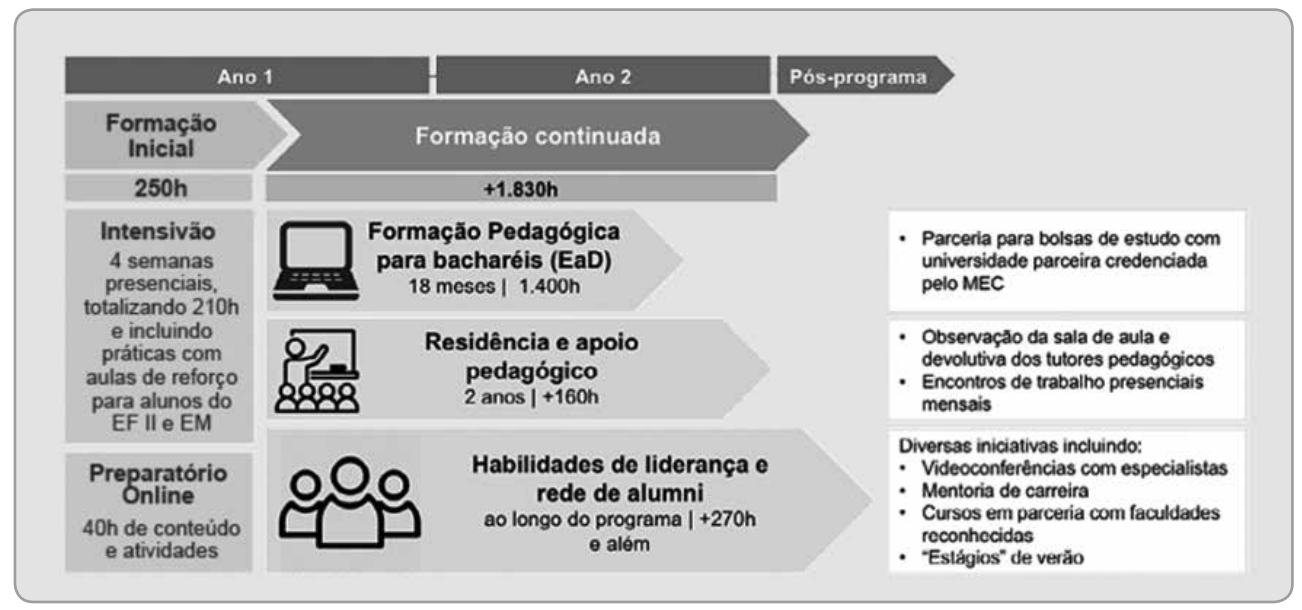

Fonte: Página do ENSINA BRASIL, acessado em 06/08/2019, disponível em: https://docs.wixstatic.com/ugd/033518_2ce100c1f5954515975bf10f9a192b37.pdf

Este tipo de programa não é incompatível com a política curricular BNCC. O Ensina Brasil está em consonância com os apoiadores de políticas neoliberais gerencialistas. $\mathrm{O}$ programa é apoiado ou tem como parceiros, por exemplo, Itaú Social, Insper, Fundação Lemann, Elos Educacional, Kroton, dentre outros.

Sua finalidade é retirar das universidades a formação docente e mostrar que é possível jovens recém graduados treinados poderem tornar-se docentes, por um período curto de dois ou três anos. Não há contradição com a BNCC, pois basta aplicar materiais e pacotes já orientados para a consecução do currículo previsto na base. Atualmente, com a possibilidade legal de terceirização das atividades fim e do trabalho voluntário, ficou mais flexível e possível que esses jovens recrutados sejam remunerados por prefeituras, como trabalho temporário, e com bolsas articuladas pelas entidades parceiras. 
A meta não é longevidade para esse tipo de programa. A meta é flexibilizar o trabalho docente e a sua formação. Nesse sentido, a formação docente feita em cursos universitários, baseada no ensino e na pesquisa, está ameaçada e poderá ser substituída por outra, realizada em cursos de fato aligeirados e baratos. Como não se vislumbra a médio prazo uma melhoria das condições de trabalho e de salário que possam atrair jovens talentosos para a profissão, há uma possibilidade real de que programas desse tipo e cursos medíocres ganhem espaço na formação docente. A irresponsabilidade dessas políticas é imensa, pois, diferentemente do que apregoam os reformistas, tais políticas não são baseadas em evidências.

O que este texto tenta demonstrar é que há uma agenda global que vai se estruturando localmente, a partir de grupos hegemônicos, nem sempre coesos, ora mais liberais, ora mais ultraliberais, ora neoconservadores e autoritários, mas que têm obtido sucesso em impor sua agenda que assume formas múltiplas de atender os ditames do mercado e dos interesses conservadores. A BNCC está no centro desses interesses e, a meu ver, tem servido tanto para aprofundar interesses de mercado como interesses em torno do controle sobre o conhecimento, com as investidas ideológicas conservadoras.

A resistência tem sido forte e poderá ser longa, mas não se pode desistir da busca de uma educação social, coletiva, culturalmente relevante e que busque uma justiça curricular e social.

Recebido em 10/06/2019 e aprovado em 25/06/2019

\section{Notas}

1 Tradução livre.

2 Ver Lima e Hypolito (prelo).

3 Ver o artigo de Avelar e Ball (2019) sobre o mapeamento desses grupos ativos nas políticas educacionais no Brasil.

4 Indico esta tese que apresenta dados muito contundentes sobre os processos de privatização, consultorias privadas e utilização de plataformas em sistemas públicos de ensino (SILVA, 2018).

\section{Referências}

APPLE, Michael W. Conhecimento oficial: a educação democrática numa era conservadora. $2^{a}$. ed. Petrópolis: Vozes, 1999. 
APPLE, Michael W. Política cultural e educação. São Paulo: Cortez, 2000.

APPLE, Michael W. Educando à direita: mercados, padrões, Deus e desigualdade. São Paulo: Cortez: Instituto Paulo Freire, 2003.

AVELAR, Marina; BALL, Stephen J. Mapping new philanthropy and the heterarchical state: The Mobilization for the National Learning Standards in Brazil. International Journal of Educational Development, n. 64, p. 65-73, 2019.

BALL, Stephen J. Educação Global S.A.: Novas redes políticas e o imaginário neoliberal. Ponta Grossa: Editora UEPG, 2014.

BALL, Stephen J. Novos Estados, nova governança e nova política educacional. In: Apple, M. W., Ball, S.J.; Gandin, L.A. (org.) Sociologia da Educação: análise internacional. Porto Alegre: Penso, 2013.

BALL, Stephen J.; BAILEY, Patrick; MENA, Paula; DEL MONTE, Pablo; SANTORI, Diego; TSENG, Chun-ying; YOUNG, Helen; e OLMEDO, Antonio. A constituição da subjetividade docente no Brasil: um contexto global. Revista Educação em Questão, Natal, v. 46, n. 32, p. 9-36, maio/ago. 2013.

BALL, S. J., MAGUIRE, M.; BRAUN, A. How schools do policy - policy enactments in Secondary Schools. London: Routledge, 2012.

BANCO MUNDIAL. Um ajuste justo: Análise da eficiência e equidade do gasto público no Brasil. 2017. Acesso em 01/06/2019, disponível em: https://www.worldbank.org/pt/country/brazil/publication/ brazil-expenditure-review-report

BRASIL. Secretaria de Educação Fundamental. Parâmetros curriculares nacionais: introdução aos parâmetros curriculares nacionais. Brasília: MEC/SEF, 1997.126p

BRUNS, Barbara; LUQUE, Javier. Great Teachers: How to Raise Student Learning in Latin America and the Caribbean. Washington, DC: World Bank, 2015. Acesso em 01/06/2019, disponível em: https:// openknowledge.worldbank.org/handle/10986/20488

FREITAS, Luiz C. de. A Reforma Empresarial da educação: nova direita, velhas ideias. São Paulo: Expressão Popular, 2018.

HYPOLITO, Álvaro M. Currículo e projeto político-pedagógico: implicações na gestão e no trabalho docente. Cadernos de Educação, Brasília, n. 26, p. 11-26, jan.jjun., 2014. Disponível em: http://cnte.org. br/images/stories/cadernos_educacao/cadernos_educacao_26.pdf

HYPOLITO, Álvaro M. Trabalho docente e o novo Plano Nacional de Educação: valorização, formação e condições de trabalho. Cadernos CEDES, v. 35, p. 517-534, 2015.

IVO, Andressa A.; HYPOLITO, Álvaro M. Sistemas de avaliação em larga escala e repercussões em diferentes contextos escolares: limites da padronização Gerencialista. RBPAE, v. 33, n. 3, p. 791 - 809, set./dez. 2017

LIMA, Iana G.; HYPOLITO, Álvaro M. A expansão do neoconservadorismo na educação brasileira. Educação e Pesquisa. (prelo)

LEITE, Maria C. L.; HYPOLITO, Álvaro M.; DALL'IGNA, Maria A.; CÓSSIO, Maria de F.; MARCOLLA, Valdinei. Gestión escolar democrática: una construcción contextualizada en escuelas municipales de la ciudad de Pelotas, RS, Brasil. Revista Mexicana de Investigación Educativa, v. 17, p. 89-113, 2012.

MARTINS, Erika. M. Todos pela Educação? Como os empresários estão determinando a política educacional brasileira. Rio de Janeiro: Editora Lamparina, 2016. 
RAVITCH, Diane. Vida e morte do grande sistema escolar americano: como os testes padronizados e o modelo de mercado ameaçam a educação. Porto Alegre: Sulina, 2011.

SANTOS, Boaventura de S. A Globalização e as Ciências Sociais. São Paulo: Cortez Editora, 2002.

SILVA, Maria E. da. Redes de influência em Mato Grosso - O Estado e as Parcerias Público-Privadas e a reconfiguração da política educacional da Rede Estadual de Ensino. Pelotas: UFPel, 2018. Tese de Doutorado.

SILVA, Tomaz Tadeu da; GENTILI, Pablo A. A. (Org.). Escola S. A.: quem ganha e quem perda no mercado educacional do neoliberalismo. Brasília, DF: CNTE, 1996.

VERGER, A., PARCERISA, L., \& FONTDEVILA, C. The growth and spread of large-scale assessments and test-based accountabilities: A political sociology of global education reforms. Educational Review, v. 71, n. 01, p. 1-26, 2018. DOI:10.1080/00131911.2019.1522045

WEINER, L., COMPTON, M. Understanding the aims and assumptions of the World Bank's report "Great Teachers" for Latin America and the Caribbean. Critical Education, v. 7, n. 11, 2016. Acesso em 01/06/2019, disponível em: http://ojs.library.ubc.ca/index.php/criticaled/article/view/186145 